\title{
CARACTERIZAÇÃO FÍSICO-QUÍMICA DO BIODIESEL PRODUZIDO NUMA COLUNA DE DESTILAÇÃO REACTIVA A PARTIR DO ÓLEO DE PALMA
}

\author{
KÁTIA C. P. GABRIEL ${ }^{1,2}$, A. A. CHIVANGA BARROS ${ }^{1}$ e MARIA JOANA NEIVA \\ CORREIA $^{2}$
}

${ }^{1}$ Instituto Superior Politécnico de Tecnologias e Ciências, Departamento de Engenharias e Tecnologias - Av. Luanda Sul, Rua Lateral Via S10, Talatona Município de Belas, Luanda - Angola.

${ }^{2}$ Departamento de Engenharia Química, Instituto Superior Técnico, Universidade de Lisboa, Av. Rovisco Pais, 1049-001, Lisboa - Portugal.

Email de contacto: chivanga.barros@isptec.co.ao; katia.gabriel@isptec.co.ao; qjnc@ist.utl.pt

RESUMO: O processo de extração do óleo de palma, envolve as operações de cozimento, extração mecânica e extração com água quente, seguido de operações de evaporação. $\mathrm{O}$ óleo de palma produzido contém grande concentração de triglicerídeos característicos e ácidos gordos livres e pode ser utilizado como matéria-prima para a produção de biodiesel por reação química de transesterificação. Os processos de produção de biodiesel são normalmente realizados em bateladas com tempos de operação elevados e limitação na capacidade produtiva. Assim, no presente trabalho, apresentam-se estudos preliminares de produção de biodiesel em uma coluna de destilação reactiva, com enchimento e controlo de temperatura, utilizando etanol e $\mathrm{KOH}$ como catalisador homogêneo. A metodologia consistiu no carregamento do refervedor com excesso de álcool, seguindo-se a alimentação da coluna com o óleo de palma e com a quantidade de etanol estequiométrico contendo o catalisador dissolvido. A instalação permite alteração nos fluxos de calor do refervedor e determinar os perfis de $\mathrm{T}$ e $\mathrm{X}$ dos esteres ao longo da coluna de destilação reactiva.

Palavras-chave: Óleo de Palma, Biodiesel, Coluna de Destilação Reactiva

\section{INTRODUÇÃO}

Biodiesel é um combustível diesel alternativo, produzido a partir de fontes biológicas renováveis, tais como óleos vegetais e gorduras de origem animal. É biodegradável e não tóxico (KRAWCZYK, T., 1996). Devido ao aumento dos preços do petróleo, aos recursos limitados de petróleo fóssil e as preocupações ambientais, tem sido foco de investigação na perspectiva da utilização de matérias-primas renováveis para a produção de combustíveis. Em termos ambientais, a utilização de biodiesel permite reduzir as emissões de $\mathrm{CO}_{2}$ fóssil e permite a redução 
efectiva das emissões de diversos poluentes atmosféricos policíclicos (Balat et al., 2009). Em todo mundo, as matérias-primas mais utilizadas para a produção de biodiesel são óleos vegetais como os óleos de soja, colza e palma. A escolha da matéria-prima ou mistura de matérias-primas é função da localização geográfica, custos e propriedades físico-químicas exigidas para a produção do biodiesel como óleos utilizados na sua produção (Baptista et al., 2008).

Neste trabalho a matéria-prima selecionada para a produção do biodiesel foi o óleo de palma ou de dendém que faz parte do quotidiano de muitos angolanos na culinária para confeição de vários pratos como o feijão de óleo de palma, acompanhante no mufete prato típico da capital de Angola. É um óleo rico em caraotenoídes e outros compostos nutracêuticos. Além do mais, o referido óleo concentra quantidades significativas de triglicerídeos e ácidos gordos livres que podem ser convertidos em ésteres através de reacção de esterificação/transesterificação (Figura 1). Na reacção de transesterificação, um mol de triglicerídeo reage com três mols de álcool, usualmente o metanol ou etanol, na presença de um catalisador, que pode ser ácido ou básico, homogêneo, heterogêneo ou enzimático.

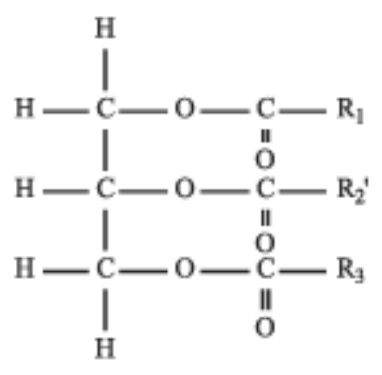<smiles>[R]OC([R])=O</smiles><smiles>CC(O)C(O)CO</smiles>

Figura 1 - Representação esquemática das reacções de esterificação transesterificação.

No presente trabalho, realizou-se a reação de transesterificação numa coluna de destilação reactiva cuja a intensidade de mistura é baseada na interação entre as fases líquida e vapor, em contracorrente. Nesta operação ocorre a reação química de transesterificação e destilação fraccionada que garante a purificação permanente do álcool em excesso utilizado na mistura. Esta técnica, que integra a reação química e a separação, também é conhecida como destilação catalítica (DC) e é utilizada, geralmente, para reacções catalíticas reversíveis e exotérmicas (PERRY et al., 1986).

\section{MATERIAIS E MÉTODOS}

Todos os ensaios foram realizados nos laboratórios do Instituto Superior Politécnico de Tecnologias e Ciências (ISPTEC) em Luanda (Angola). As amostras de óleo de palma utilizadas para a produção do biodiesel foram produzidas na Fazenda Esperança localizada na comuna do Nhime que dista $42 \mathrm{kms}$ da cidade do Sumbe, capital da Província de Kwanza Sul. Em seguida são apresentados todos os procedimentos adotados para a execução dos ensaios experimentais de produção do óleo de palma, da reacção de transesterificação com catalisador homogéneo numa coluna de destilação reactiva, bem como as técnicas de caracterização do óleo de palma e do biodiesel produzido. 


\subsection{Produção do Óleo de Palma}

A produção do óleo de palma foi realizada utilizando-se os seguintes procedimentos:

a) Colecta dos cachos de dendém nas palmeiras;

b) Separação dos cachos para retirada manual dos frutos e posterior separação manualmente;

c) Os frutos de dendém separados foram cozidos numa grande caldeira com massa de água reduzida;

d) Depois de cozidos, os frutos foram prensados numa prensa hidráulica. Esta prensagem permite separar a polpa de dendém das cascas e amêndoas. As cascas resultantes são utilizadas como ração animal;

e) A polpa extraída é cozida na caldeira com água para extrair as impurezas que são solúveis em água;

f) Depois de, aproximadamente, 3 horas de cozedura, obtém-se uma mistura constituída por duas fases, sendo o óleo de palma a fase menos densa que é separada por decantação.

O óleo assim produzido foi transportado para os laboratórios do ISPTEC, em Luanda, para ser utilizado nos ensaios de produção de biodiesel, de acordo com os procedimentos descritos neste trabalho.

\subsection{Produção do Biodiesel na Coluna de Destilação Reactiva}

A reacção de produção de biodiesel foi realizada numa coluna de destilação reactiva conforme mostra a Figura 2.

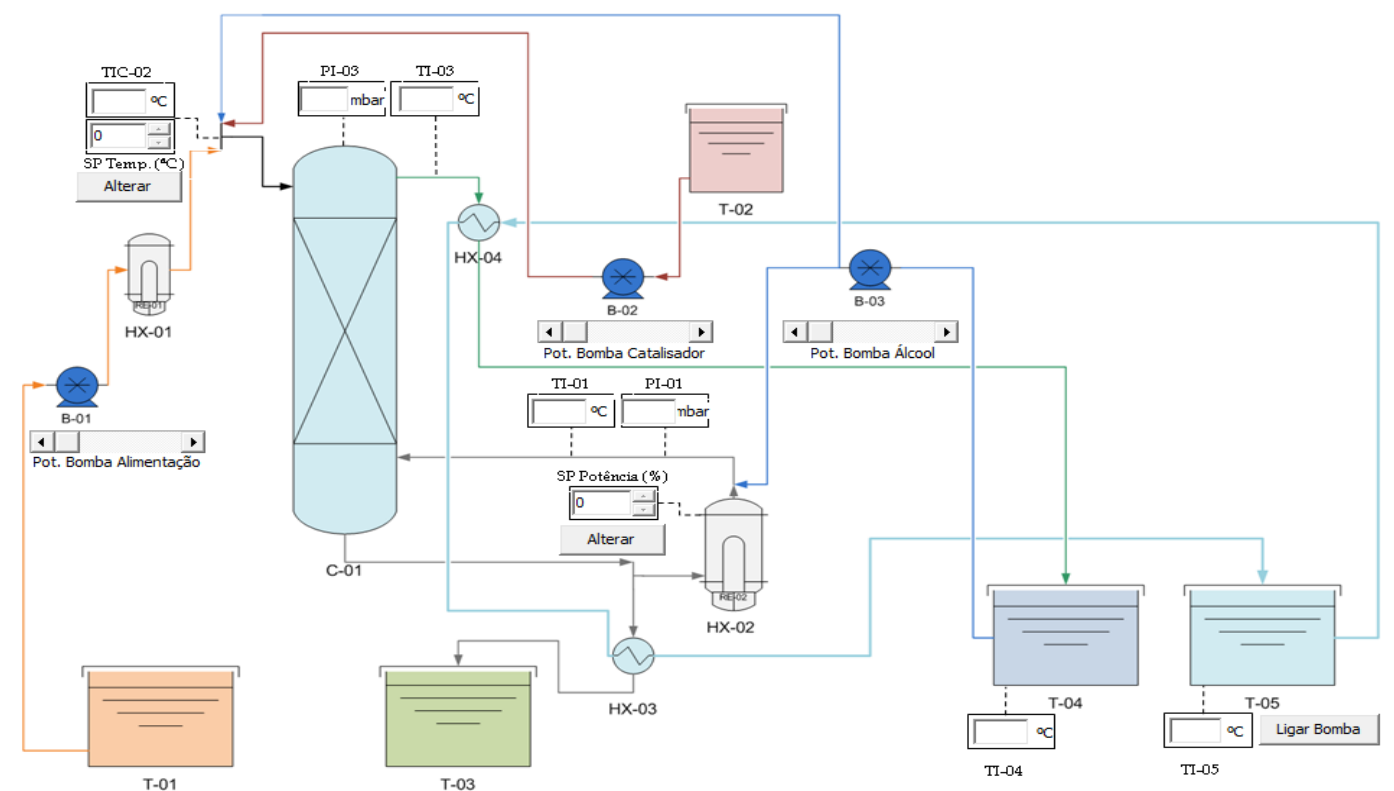

Legenda:

B-01 - Bomba de óleo; B-02 - Bomba do catalisador; B-03 - Bomba do álcool; C-01 - Coluna de destilação reactiva.

HX- 01 - Refervedor de alimentação; HX-02 - Refervedor de álcool; HX-03 - Condensador de Base; HX-04 - Condensador de topo;

T-01 - Tanque pulmão de óleo; T-02 - Tanque pulmão do catalisador; T-03 - Tanque pulmão de álcool; T-04 - Tanque pulmão de biodiesel;

Figura 2: Fluxograma da produção de biodiesel na coluna de destilação reactiva. 
a) 5 litros de etanol foram inseridos no refervedor e aquecidos até $70^{\circ} \mathrm{C}$. Os vapores ascendentes foram condensados e a coluna alimentada progressivamente na mesma relação da retirada dos produtos;

b) A operação da coluna foi realizada à pressão atmosférica, devido a abertura da parte superior do condensador para a atmosfera;

c) Fez-se o controle da coluna para garantir que a temperatura na base fosse mantida durante o processo a $70^{\circ} \mathrm{C}$;

d) Com a estabilização da coluna, em termos das vazões e da temperatura, iniciouse a alimentação, na parte superior da coluna, da mistura dos reagentes (óleo de palma e catalisador dissolvido no álcool estequeométrico), previamente aquecidos a $50^{\circ} \mathrm{C}$;

e) Esta mistura descende totalmente na forma líquida até à base da coluna com borbulhamento intenso decorrente da interação entre as fases vapor ascendente e líquido descendente cuja intensificação da mistura deve-se à presença dos recheios utilizados para aumentar a área de transferência de massa;

f) Neste percurso são retiradas nas laterais amostras do líquido descendente para posterior caracterização;

g) Nos testes preliminares realizados até então foi utilizada uma razão molar etanol:óleo de 4:1 e uma concentração de catalisador, $\mathrm{KOH}$, de 1\% (massa catalisador por massa do óleo de palma);

h) O tempo do escoamento dos reagentes foi estimado em aproximadamente 20 minutos;

i) Os produtos da reação foram coletados na base da coluna e redirecionados para o tanque de biodiesel para posterior purificação e caracterização;

j) Como destacado, foram retiradas amostras do produto formado das diferentes secções da coluna de destilação reactiva e o álcool em excesso foi separado do produto de reacção por evaporação num evaporador rotativo;

k) Os produtos de reacção foram colocados num funil de separação e deixado em repouso para a separação de fases, sendo o biodiesel a fase leve e o glicerol a fase pesada.

\subsection{Caracterização do óleo de palma e do produto de reacção}

O índice de acidez do óleo e dos produtos da reacção foram determinados por titulação com uma solução de $\mathrm{KOH} 0,1 \mathrm{M}$, enquanto que a viscosidade foi determinada utilizando um viscosímetro de Ostwald e a massa específica determinada pelo método do picnómetro.

O índice de refração do produto foi medido utilizando-se um refratómetro tipo Abbe. Foram também recolhidos os espectros de infravermelho médio (FTIR) do óleo e do produto da reacção num equipamento da ThermoScientific, modelo: nicolet is 5 . 


\section{RESULTADOS E DISCUSSÕES}

\subsection{Caracterização do óleo de palma}

Os parâmetros físico-químicos para caracterização do óleo de palma utilizado nos ensaios são apresentados na Tabela 1 , abaixo.

Tabela 1: Caracterização Físico-Química do Óleo de Palma

\begin{tabular}{c|c}
\hline Parâmetro & Resultados obtidos \\
\hline Viscosidade $\left[\mathrm{mm}^{2} / \mathrm{s}\right] \mathrm{a} 40^{\circ} \mathrm{C}$ & 15,85 \\
\hline Massa Específica $\left[\mathrm{kg} / \mathrm{m}^{3}\right]$ & 908,57 \\
\hline Índice de Acidez $[\mathrm{mg} \mathrm{KOH} / \mathrm{g}]$ & 16,12 \\
\hline Índice de Refração & 1,465 \\
\hline
\end{tabular}

A Figura 3 apresenta o espectro de infravermelho do óleo de palma que mostra os comprimentos de onda característicos de óleo com concentração grupos orgânicos.

O espectro do óleo de palma apresenta, como esperado, uma banda a $720 \mathrm{~cm}^{-1}$ característica das vibrações de bending do $-\left(\mathrm{CH}_{2}\right)$ n- e $-\mathrm{HC}=\mathrm{CH}-$ cis, bem como as bandas na zona de $1160-1115 \mathrm{~cm}^{-1}$ atribuídas devido as vibrações stretching e bending do $-\mathrm{C}-\mathrm{O}$ e $\mathrm{CH}_{2}$ - O pico localizado na faixa de $1700 \mathrm{~cm}^{-1}$ é atribuído à vibração de stretching do $\mathrm{C}=\mathrm{O}$ enquanto o pico localizado a na faixa de $2850 \mathrm{~cm}^{-1}$ deve-se à vibração de stretch simétrico do $\mathrm{CH}\left(-\mathrm{CH}_{2}-\right)$ e aquele localizado a $2920 \mathrm{~cm}^{-1}$ deve-se à vibração de stretch assimétrico do $\mathrm{CH}\left(-\mathrm{CH}_{2}-\right)$ ou seja das ligações saturadas que são abundantes no óleo de palma [Baptista, P., 2008].

\subsection{Caracterização do Biodiesel Produzido}

O biodiesel sintetizado mediante a metodologia descrita acima foi caracterizado mediante a medição dos parâmetros apresentados na Tabela 2. Nesta tabela observa-se que os parâmetros como viscosidade e massa específica atendem as especificações Europeias, garantindo desta forma a confiabilidade da metodologia estabelecida. O desvio no índice de acidez observado deve-se às características do óleo de palma utilizado que contém valor elevado deste parâmetro. Contudo, nos estudos realizados utilizando-se óleos com elevado índice de acidez, é comum realizar reações em duas etapas (esterificação seguida da transesterificação) mas, o procedimento adotado se devidamente ajustado possibilita eliminar a esterificação pois o índice de acidez reduzse de 16,12 para 1,30 (BARROS, A. et al., 2008). 
Tabela 2: Caracterização Físico-Química do Biodiesel

\begin{tabular}{c|c|c}
\hline Parâmetro & Norma de Europeia & Resultados obtidos \\
\hline Viscosidade $\left[\mathrm{mm}^{2} / \mathrm{s}\right] \mathrm{à} 40^{\circ} \mathrm{C}$ & $3,0-6,0$ & 2,41 \\
\hline Massa Específica $\left[\mathrm{kg} / \mathrm{m}^{3}\right]$ & $850,0-900,0$ & 863,3 \\
\hline Índice de Acidez $[\mathrm{mg} \mathrm{KOH} / \mathrm{g}]$ & 0,5 & 1,30 \\
\hline Índice de Refração & ------- & 1,391 \\
\hline
\end{tabular}

Foi igualmente recolhido o espectro de infravermelho do produto obtido que é apresentado na Figura 4. De referir que foi analisada uma amostra de biodiesel bruto ou seja possivelmente contaminado com metanol, glicerol, sabões entre outros. De facto, a presença da banda acentuada a $\approx 3300 \mathrm{~cm}-1$, atribuída ao stretching $\mathrm{O}-\mathrm{H}$, comprova a presença de grupos $\mathrm{OH}$ do metanol e/ou glicerol na amostra.

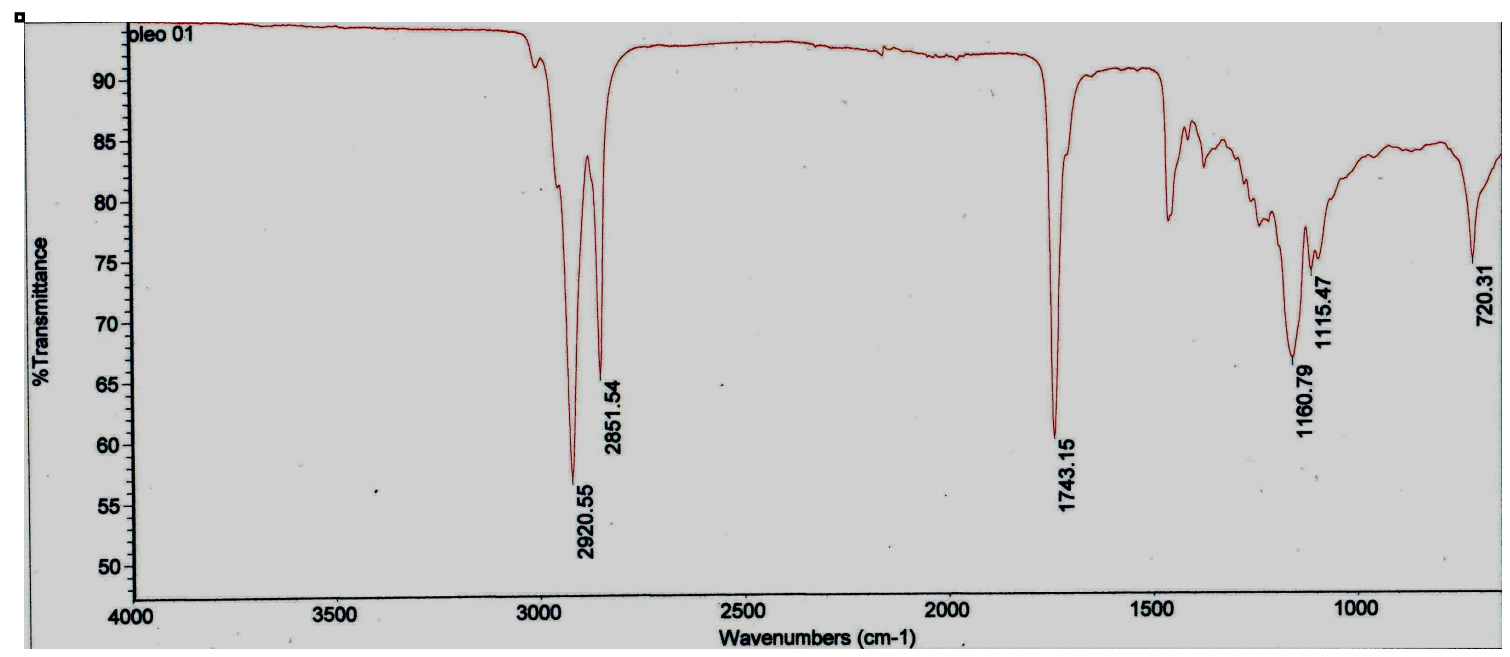

Figura 3: Espectro de infravermelho do óleo de palma.

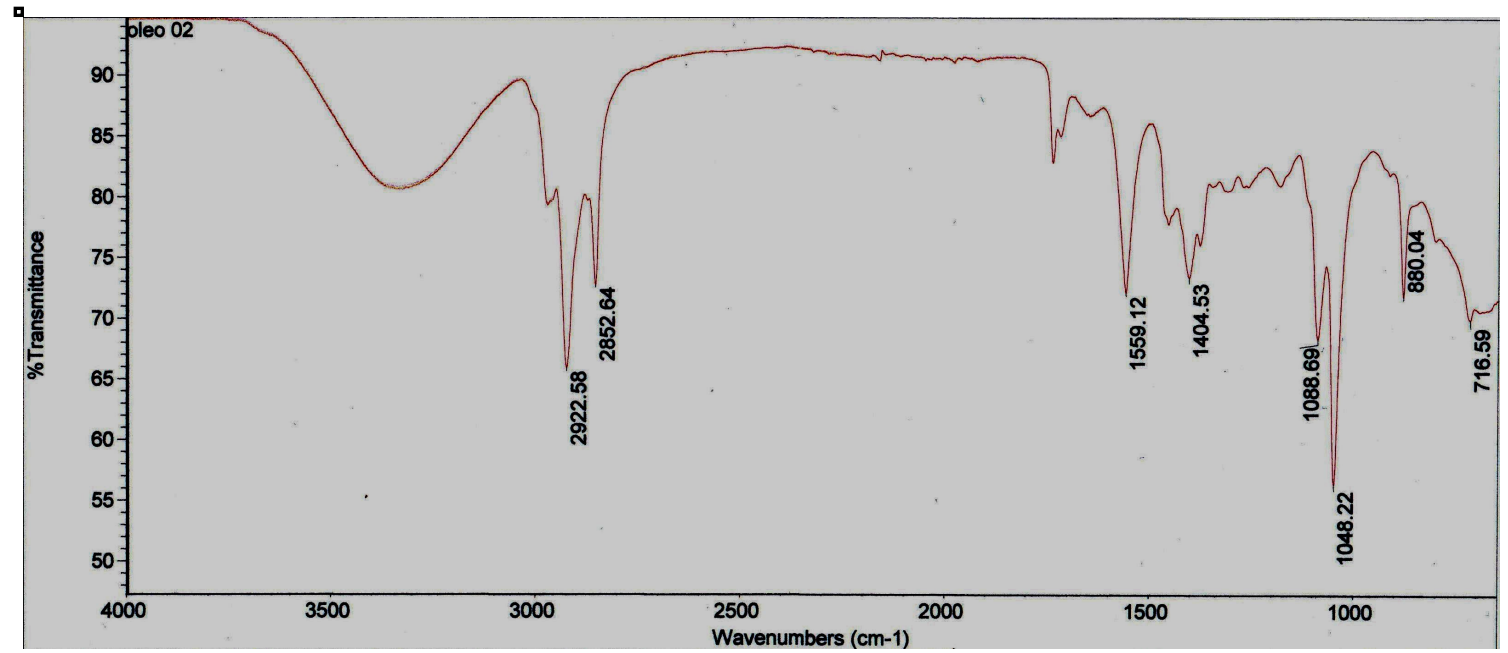

Figura 4: Espectro de infravermelho do produto obtido. 
O espectro descrito na Figura 4 mostra que, os principais picos característicos de esteres etílicos ou metílicos estão presentes no espectro, mas com baixa intensidade decorrente da ausência de procedimentos de purificação que visam eliminar as impurezas resultantes deste processo. Com a implementação dos processos secundários de purificação, espera-se obter um biodiesel com as características descritas na literatura baseado na descrição do espectro de infravermelho.

\section{CONCLUSÃO}

Com os resultados descritos ao longo deste trabalho, pode-se concluir que:

i. As metodologias adotadas para a produção de biodiesel por destilação reactiva possibilita obter biodiesel que atende, preliminarmente, as especificações descritas nas normas europeias, principalmente aquelas relacionadas com a massa específica e a viscosidade. Os demais parâmetros podem ser melhorados com a otimização da reação de transesterificação em coluna de destilação reactiva;

ii. A coluna de destilação reativa, descrita neste trabalho, é um instrumento laboratorial que pode ser utilizada na perspectiva de produção de biocombustível em processos contínuos;

iii. Que o biodiesel produzido a partir de óleo de palma, matéria-prima com elevado índice de acidez, numa coluna de destilação reactiva promove a redução significativa deste parâmetro o que elimina a etapa de esterificação comummente utilizada quando da produção de biodiesel com elevado índice de acidez.

\section{REFERENCIAS BIBLIOGRÁFICAS}

1. KRAWCZYK, T., Biodiesel - Alternative Fuel Makes Inroads but Hurdles Remain. INFORM 7, 801-829, 1996.

2. SHAY, E.G.,. Diesel fuel from vegetable oils: status and opportunities. Biomass and Bioenergy 4, 227-242, 1993

3. KNOTHE, G. et al. Manual de Biodiesel. Curitiba: Edgard Blücher, 2006.

4. PERRY H. R., CHILTON H. C., Manual de Engenharia Química, Cinética de Reação, Projeto de Reator e Termodinâmica, $5^{\text {a }}$ ed., Editora: Guanabara Dois, 1986.

5. BAPTISTA, PATRICÍA et al., Monitoring the Quality of Oils for Biodiesel Production Using Multivariate Near Infrared Spectroscopy Models, J. of Near Infrared Spectroscopy, 16, 445-454, 2008

6. BAPTISTA, PATRICÍA et al., Multivariate Near Infrared Spectroscopy Models for Predicting the Iodine Value, CFPP, Kinematic Viscosity at $40 \circ \mathrm{C}$ and Density at $15 \circ \mathbf{C}$ of Biodiesel, Talanta, 77, 144-151, 2008

7. BARROS, ANTÓNIO ANDRE CHIVANGA; WUST, ELISIANE; MEIER, H. F., Estudo da Viabilidade Técnico-Científica da Produção de Biodiesel a partir de Resíduos Gordurosos, Eng. Sanit. Ambient. Vol.13, 255-262,2008. 